\title{
ADSORÇÃO POR CARVÃO ATIVADO PULVERIZADO COMO PÓS-TRATAMENTO DE LIXIVIADO DE ATERROS SANITÁRIO
}

\author{
Jandiara Damaris Campos Pozzetti \\ João Victor Amaral Ferreira \\ Marcos Batista Mendes \\ Vilson Gomes da Assunção Junior
}

RESUMO: A escolha de um sistema eficiente de tratamento para o lixiviado é um dos grandes desafios no gerenciamento de aterros, devido à alta variabilidade de suas características e à presença de compostos recalcitrantes. As formas mais utilizadas de tratamento do lixiviado são baseadas em processos biológicos e físico-químicos. $\mathrm{O}$ processo de adsorção por carvão ativado pode ser utilizado para adsorver moléculas orgânicas que causam sabor e odor, mutagenicidade, toxicidade e matéria orgânica responsável pela cor e é caracterizado por possuir área superficial interna e porosidade altamente desenvolvida, permitindo a adsorção de moléculas em fase líquida e gasosa, tendo como importância principal, para o processo de adsorção, o desenvolvimento de micro e mesoporos. Sendo assim, este trabalho teve como objetivo avaliar a eficiência da adsorção dos Carvões Ativados Pulverizados - CAPs pré-selecionados para aplicação no pós-tratamento de lixiviado estabilizado de aterro sanitário, tratado previamente por stripping de amônia, seguido de tratamento biológico por lodos ativados em bateladas sequenciais mediante remoção de matéria orgânica correlacionada à cor verdadeira. Os CAPs amostrados foram caracterizados em relação ao Número de lodo - NI, Índice de Fenol - IF e Índice de Azul de Metileno - IAM, após caracterização, foram préselecionados os CAPs A, B e C e submetidos ao experimento de adsorção. $O$ experimento de adsorção demonstrou eficiência limitada na adsorção de cor verdadeira 
do lixiviado de estudo, uma vez que para os carvões pré-selecionados, foram necessárias dosagens elevadas para atingir remoções significativas deste parâmetro.

\section{INTRODUÇÃO}

Existem várias formas de disposição de resíduos sólidos urbanos, podendo-se destacar: o lixão, o aterro controlado e o aterro sanitário (SCHALCH e LOPES, 2004). Dentre essas formas, o aterro sanitário é o método mais adequado de disposição final de resíduos sólidos e tem como objetivo dispor os resíduos sólidos no solo, de forma segura e controlada, garantindo a preservação do ambiente, a higiene e a saúde pública. Estes devem ser impermeabilizados em sua base e contar com sistemas de drenagem da água infiltrada e dos gases gerados. Quando chove, a água que percola o aterro e lixivia uma série de contaminantes. Esse percolado ou lixiviado torna-se então um problema, já que contêm grandes quantidades de matéria orgânica, nitrogênio amoniacal, metais pesados, sais inorgânicos e organoclorados que são substâncias tóxicas aos organismos vivos e aos ecossistemas (WEl et al., 2010).

Visando à preservação da vida aquática e a manutenção da qualidade dos corpos hídricos, padrões de lançamento e de qualidade de água foram estabelecidos pelas legislações vigentes CONAMA 357/2005, CONAMA 430/2011, CEMA №. 0070/2009 e CEMA №. 081/2010, incluindo valores máximos de Cor verdadeira, DQO, nitrogênio amoniacal, metais, toxicidade, entre outros, o que requer o tratamento do lixiviado de aterro sanitário antes de seu lançamento no corpo receptor.

A escolha de um sistema eficiente de tratamento desse efluente é um dos grandes desafios no gerenciamento de aterros, devido à alta variabilidade de suas características e à presença de compostos recalcitrantes.

De acordo com Pacheco e Peralta (2004), as formas mais utilizadas de tratamento de lixiviado são baseadas em processos biológicos e físico-químicos. O biológico pode ser realizado por processos aeróbios, anaeróbios e facultativos, mas possuem baixa remoção de compostos recalcitrantes e coloridos. Já os processos físico-químicos, 
através de coagulação química, floculação e sedimentação/flotação, adsorção, separação por membranas, oxidação e precipitação química, apresentam maior eficiência na remoção dos compostos recalcitrantes, em comparação ao biológico.

A técnica a ser empregada para o tratamento do lixiviado, depende das características do mesmo e da qualidade do efluente que se deseja obter para o lançamento e disposição no meio ambiente.

O processo de adsorção por carvão ativado, por exemplo, pode ser utilizado para adsorver moléculas orgânicas que causam sabor e odor, mutagenicidade, toxicidade e matéria orgânica responsável pela cor (KAWAHIGASHI, 2012).

A capacidade adsortiva de um material depende de alguns fatores do adsorvente e das condições experimentais, como:

- Estrutura interna e forma;

- Volume e distribuição dos poros;

- Química da superfície;

- Método de ativação;

- Teor de cinzas;

- pH e temperatura;

- Grau de agitação;

- Tempo de contato entre adsorvato e adsorvente;

Entre outros fatores que podem dificultar ou favorecer o processo de adsorção (KURODA et al., 2005).

O carvão ativado é caracterizado por possuir área superficial interna e porosidade altamente desenvolvida, permitindo a adsorção de moléculas em fase líquida e gasosa, tendo como importância principal, para o processo de adsorção, o desenvolvimento de micro e mesoporos (KAWAHIGASHI, 2012). O tamanho do diâmetro dos poros é classificado em micro, meso e macroporos, conforme a IUPAC (1985), os macroporos são maiores de $50 \mathrm{~nm}$, os mesoporos entre 2 e $50 \mathrm{~nm}$ e os microporos são menores de $2 \mathrm{~nm}$.

\subsection{Objetivo}


Avaliar a eficiência da adsorção dos Carvões Ativados Pulverizados préselecionados para aplicação no pós-tratamento de lixiviado estabilizado de aterro sanitário, tratado previamente por stripping de amônia, seguido de tratamento biológico por lodos ativados em bateladas sequenciais mediante remoção de matéria orgânica correlacionada à cor verdadeira.

\section{DESENVOLVIMENTO}

\subsection{MATERIAL E MÉTODOS}

\subsubsection{Lixiviado e Carvão Ativado Pulverizado - CAP}

O lixiviado bruto foi coletado no aterro controlado de resíduos sólidos domiciliares da cidade de Londrina - PR, localizado às margens da estrada "Água do Limoeiro", no lote 23-C da Gleba Cambé em funcionamento no período de 1974-2010 com características de lixiviado estabilizado. Após a coleta, o lixiviado foi armazenado em um reservatório de fibra de vidro com capacidade volumétrica de $15 \mathrm{~m}^{3}$ no Laboratório de Hidráulica e Saneamento da UEL.

O lixiviado coletado foi submetido ao tratamento preliminar por stripping de amônia e tratamento biológico por lodos ativados, em instalação piloto de $1 \mathrm{~m}^{3}$ de capacidade, e bateladas sequenciais para remoção da série nitrogenada, segundo metodologias utilizadas por Hossaka (2008), Alvim (2010) e Felici (2010), resultando assim no lixiviado de estudo.

Foram adquiridas quatorze amostras de CAPs disponíveis no mercado nacional e internacional com condições diversificadas de origem, matéria prima, método de ativação e propriedades físicas e químicas.

Após caracterização em relação ao Número de lodo - NI e Índice de Fenol - IF, parâmetros estabelecidos pela norma brasileira NBR 11834/1991 EB - 2133 e Índice de Azul de Metileno - IAM estabelecido pela Japanese Industrial Standard - JIS K 147, foram pré-selecionados os CAPs A, B e C com as seguintes características:

- A - Nacional de origem vegetal proveniente do pinus, resultante do método de ativação física; 
- B - Importado de origem animal proveniente do osso, resultante do método de ativação química; e

- C - Nacional de origem vegetal proveniente da madeira, resultante do método de ativação física;

\subsubsection{Experimento de adsorção}

Para avaliar a capacidade de adsorção dos CAPs pré-selecionados em relação à adsorção de matéria orgânica correlacionada à cor verdadeira residual, o experimento foi realizado em escala de bancada para as dosagens de CAP de 1, 3, 5, 7 e $9 \mathrm{~g} \mathrm{~L}^{-1} \mathrm{com}$ ajuste do valor de pH em 4,0, utilizando-se solução concentrada de ácido clorídrico. Foram adotados como parâmetros de controle operacionais:

Tempo médio de mistura rápida $\mathrm{Tmr}=1 \mathrm{~min}$;

Gradiente de velocidade médio de mistura rápida $\mathrm{Gmr}=600 \mathrm{~s}^{-1}$;

Tempo médio de mistura lenta $\mathrm{Tml}=80 \mathrm{~min}$;

Gradiente de velocidade médio de mistura lenta $\mathrm{Gml}=120 \mathrm{~s}^{-1} \mathrm{e}$;

O experimento foi realizado em reatores estáticos - Jarteste (Nova Ética 218/6LDBE) - Figura 1, composto por 6 jarros de acrílico transparente de 2 L, tacômetro digital para visualização da rotação (até $600 \mathrm{rpm} \pm 2 \%$ ), o que confere gradiente de velocidade de até $1.200 \mathrm{~s}^{-1}$ e dispositivo para aplicação de produtos químicos nos 6 jarros simultaneamente.

Figura 1 - Foto do reatores estáticos - Jarteste com lixiviado

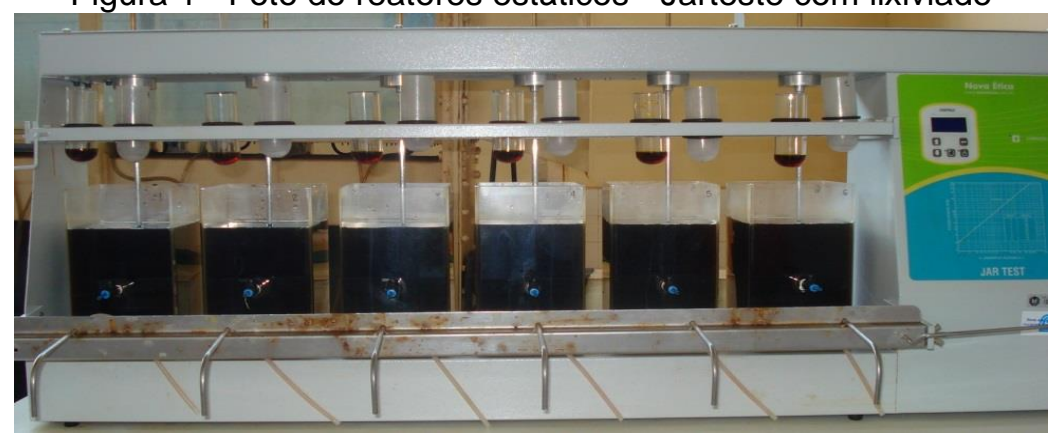

Fonte: Kawahigashi (2013)

Para ajuste de $\mathrm{pH}$ do lixiviado foi utilizado o produto químico: 
- Ácido clorídrico, solução comercial com $37 \%$ em massa e massa específica $=1,187 \mathrm{~kg}$ $\mathrm{L}^{-1}$, como acidificante para preparação de solução com concentração de $150 \mathrm{~g} \mathrm{~L}^{-1}$.

A avaliação da capacidade de adsorção dos CAPs pré-selecionados foi realizada analisando-se a cor verdadeira residual do sobrenadante, filtrado previamente em membrana de éster de celulose com porosidade média de $0,45 \mu \mathrm{m}$, segundo método espectrofotométrico 2120 C do APHA, AWWA, WEF (2005) em Espectrofotômetro Cary 60 UV-Vis da Agilent.

\subsection{RESULTADOS}

\subsubsection{Lixiviado e Carvão ativado pulverizado}

Os resultados dos valores de cor verdadeira para os lixiviados bruto e tratado biologicamente, são apresentados na Tabela 1.

\begin{tabular}{ccc}
\multicolumn{3}{c}{ Tabela $1-$ Valores de cor verdadeira dos lixiviados bruto e biológico. } \\
\hline Lixiviado & pH & Cor verdadeira (uH) \\
\hline Bruto & 8,9 & 3598 \\
Após tratamento biológico & 8,5 & 3393 \\
$\begin{array}{c}\text { \% Remoção após tratamento } \\
\text { biológico }\end{array}$ & - & 6 \\
\hline
\end{tabular}

Pôde-se observar que as características do lixiviado bruto remetem a um lixiviado já estabilizado, devido aos valores elevados de pH (da ordem de 8,9) e remoção limitada de cor verdadeira (6\% apenas).

São apresentados na Tabela 2, o resultado da caracterização dos CAPs préselecionados:

Tabela 2 - Resultados da caracterização dos carvões

\begin{tabular}{ccccccc}
\hline CAP & Origem & $\begin{array}{c}\text { Matéria- } \\
\text { prima }\end{array}$ & Ativação & $\left.\begin{array}{c}\mathbf{N I} \\
(\mathbf{m g ~ g}\end{array} \mathbf{~}^{-1}\right)$ & $\begin{array}{c}\text { IAM } \\
\left(\mathbf{m g ~ g}^{-1}\right)\end{array}$ & $\begin{array}{c}\text { IF } \\
\left(\mathbf{g ~ L ~ L}^{-1}\right)\end{array}$ \\
\hline A & Vegetal & Pinus & Física & 942 & 134 & 2,07 \\
B & Animal & Osso & Química & 1130 & 203 & 2,1 \\
C & Vegetal & Madeira & Física & 1019 & 171 & - \\
\hline
\end{tabular}




\subsubsection{Experimento de adsorção}

Os resultados de cor verdadeira residual do experimento com variação nas dosagens dos CAPs são apresentados no Gráfico 1.

Gráfico 1 - Resultados de cor verdadeira residual para os CAPs A, B e C 3000

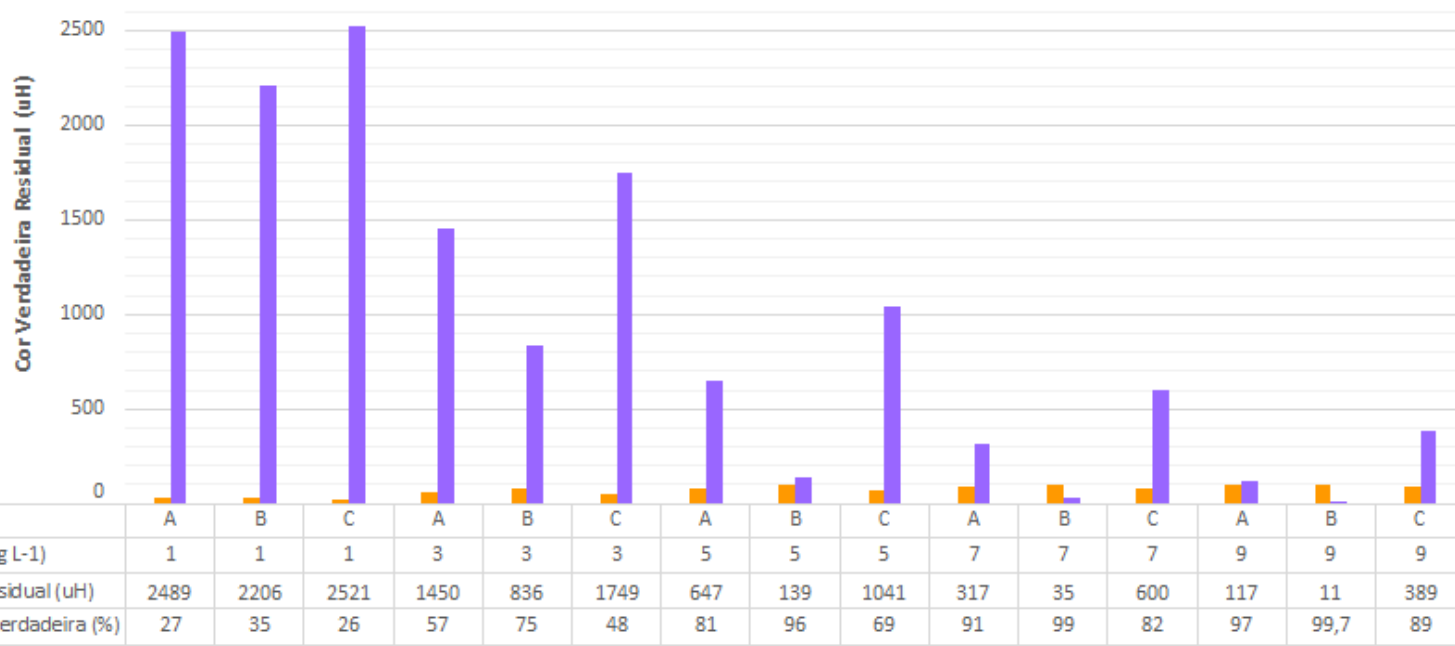

O experimento de adsorção demonstrou eficiência limitada na adsorção de cor verdadeira do lixiviado de estudo, uma vez que para os carvões pré-selecionados, foram necessárias dosagens elevadas para atingir remoções significativas deste parâmetro. Para os CAPs A e C (nacionais), mesmo com a dosagem máxima de $9 \mathrm{~g} \mathrm{~L}^{-1}$ e condições otimizadas de tratamento, não foi possível produzir efluente com qualidade compatível às condições de enquadramento para águas doces classe 2 e 3 da Resolução 357/2005 do Conama, o qual estabelece $75 \mathrm{uH}$ para cor verdadeira.

Por outro lado, de acordo com $\circ$ Gráfico 1, pode-se constatar que, a eficiência de adsorção de cor verdadeira pelo CAP B (importado) foi mais elevada, tendo produzido efluente com cor verdadeira inferior a $75 \mathrm{uH}$ já a partir da dosagem de $7 \mathrm{~g} \mathrm{~L}^{-1}$ de CAP. Para as dosagens de 7 e $9 \mathrm{~g} \mathrm{~L}^{-1}$ do CAP B os valores de cor verdadeira residual foram de $35 \mathrm{uH}$ e $11 \mathrm{uH}$, o que correpondeu a 99 e 99,7\% de remoção, respectivamente. No entanto, a necessidade do emprego de dosagens elevadas pode dificultar sua aplicação, considerando os custos associados, em um sistema de tratamento em escala real. 


\section{CONCLUSÃO}

Os carvões ativados pulverizados demonstraram eficiência limitada na adsorção de cor verdadeira do lixiviado de estudo, sendo necessárias dosagens elevadas para atingir remoções significativas deste parâmetro, o que pode dificultar sua aplicação considerando os custos associados em um sistema de tratamento em escala real.

\section{REFERÊNCIAS BIBLIOGRÁFICAS}

ALVIM, C. A. do N. Influências do pré-tratamento por stripping na desnitrificação convencional e pela via curta em RBS, aplicado ao tratamento de lixiviado de aterro sanitário. 2008. Dissertação apresentada ao Programa de Pós-Graduação em Engenharia de Edificações e Saneamento, Universidade Estadual de Londrina, Londrina, 2008.

APHA; AWWA; WEF. Standard Methods for the Examination of Water and Wastewater. 21를 ed., Washington, D. C.: APHA, 2005. American Public Health Association (APHA), American Water Works Association (AWWA), Water Environment Federation (WEF).

ASSOCIAÇÃO BRASILEIRA DE NORMAS TÉCNICAS - ABNT, Carvão ativado pulverizado para tratamento de água - especificação.NBR 11834:1991/EB - 2133. Rio de Janeiro, 1991.

ASSOCIAÇÃO BRASILEIRA DE NORMAS TÉCNICAS - ABNT, Carvão ativado pulverizado - Determinação do número de iodo - método de ensaio. NBR 12073:1991. Rio de Janeiro, 1991.

ASSOCIAÇÃO BRASILEIRA DE NORMAS TÉCNICAS - ABNT, Carvão ativado pulverizado - Determinação do índice de fenol - método de ensaio. NBR 12074:1991/MB 3411. Rio de Janeiro, 1991. 
ASSOCIAÇÃO BRASILEIRA DE NORMAS TÉCNICAS - ABNT, Amostragem de carvão ativado pulverizado - procedimento.NBR 12280:1991. Rio de Janeiro, 1991.

BRASIL, Ministério do Meio Ambiente. Conselho Nacional de Meio Ambiente. Resolução no 357, 17 de março de 2005. Dispõe sobre a classificação dos corpos 146 de água e diretrizes ambientais para o seu enquadramento, bem como estabelece as condições e padrões de lançamento de efluentes, e dá outras providências. Brasília, 2005.

BRASIL, Ministério do Meio Ambiente. Conselho Nacional de Meio Ambiente. Resolução no 430, 13 de maio de 2011. Dispõe sobre as condições e padrões de lançamento de efluentes, complementa e altera a resolução n 357 de 17 de março de 2005, do Conselho Nacional do Meio Ambiente - CONAMA. Brasília, 2011.

FELICI, E.M. Coagulação-floculação-sedimentação como pós-tratamento de efluente de sistema biológico em batelada aplicado a lixiviado de aterro de resíduos sólidos urbanos.2010. Dissertação apresentada ao Programa de Pós-Graduação em Engenharia de Edificações e Saneamento, Universidade Estadual de Londrina, Londrina, 2010.

HOSSAKA, A. L. Tratamento biológico de lixiviados de aterro sanitário, utilizando como pré-tratamento a remoção parcial de $\mathrm{N}$-amoniacal por stripping. 2008. Dissertação apresentada ao Programa de Pós-Graduação em Engenharia de Edificações e Saneamento, Universidade Estadual de Londrina, Londrina, 2008.

IUPAC Recommendations. Pure and Applied Chemistry.v. 57, n. 4, p. 603-619, 1985.

JAPANESE INDUSTRIAL STANDARD - JIS K 1474. Test Methods for activated carbon. Japanese Standards Association, Tokyo, 1991.

KAWAHIGASHI, F. Aplicabilidade do pós-tratamento de lixiviados de aterro sanitário por adsorção em carvão ativado granular e avaliação ecotoxicológica. 2012. Dissertação apresentada ao Programa de Pós-Graduação em Engenharia de Edificações e Saneamento, Universidade Estadual de Londrina, Londrina, 2012. 
KuRODA, E. K.; ALbuquerque JR, E. C.; DI BeRnARDO, L.; TROFINO, J. C. Caracterização e escolha do tipo de carvão ativado a ser empregado no tratamento de águas contendo microcistinas. XXIII Congresso Brasileiro de Engenharia Sanitária e Ambiental, Campo Grande - MS, Set. 2005.

MODIN, H.; PERSSON, K. M.; ANDERSSON, A.; VAN., P. M. Removal of metals from landfill leachate by sorption to activated carbon, bone meal and iron fines. Journal of Hazardous Materials, v. 189, n. 3, p. 749-754, Mai. 2011.

PACHECO, J. R.; PERALTA-ZAMORA, P.G. Integração de processos físico-químicos e oxidativos avançados para remediação de percolado de aterro sanitário (chorume). Rev Bras Eng Sanit Amb, v.9, n.4, p. 306-311, 2004.

PARANÁ, Conselho Nacional do Meio Ambiente. Resolução 0070/2009 - CEMA. Dispõe sobre o licenciamento ambiental, estabelece condições e critérios e dá outras providências, para Empreendimentos Industriais. Curitiba, 2009.

PARANÁ, Conselho Nacional do Meio Ambiente. Resolução 081/2010 - CEMA. Dispõe sobre critérios e padrões de ecotoxicidade para o controle de efluentes líquidos lançados em águas superficiais no estado do Paraná. Curitiba, 2010.

SCHALCH, V., LOPES, A. A. Gestão integrada dos resíduos sólidos urbanos e minimização dos impactos ambientais, ICTR - Instituto de Ciência e Tecnologia em Resíduos e Desenvolvimento Sustentável, Congresso Brasileiro de Ciência e Tecnologia em Resíduos e Desenvolvimento Sustentável, Costão do Santinho - Florianópolis - Santa Catarina 2004.

WEI, L.; TAO, H.; QIXING, Z.; SHUGUANG, Z.; FENGXIANG, L. Treatment of stabilized landfill leachate by the combined process of coagulation/flocculation and powder activated carbon adsorption. Desalination, v. 264, n. 1, p. 56-62, Ago. 2010 